\title{
Modeling Electrochemical Decomposition of Fluoroethylene Carbonate on Silicon Anode Surfaces in Lithium Ion Batteries
}

\author{
Kevin Leung, ${ }^{1 *}$ Susan B. Rempe, ${ }^{1}$ Michael E. Foster, ${ }^{1}$ Yuguang Ma,${ }^{2}$ \\ Julibeth M. Martinez del la Hoz, ${ }^{2} \mathrm{Na} \mathrm{Sai},{ }^{3}$ and Perla B. Balbuena ${ }^{2}$ \\ ${ }^{1}$ Sandia National Laboratories, MS 1415, \\ Albuquerque, NM 87185 \\ ${ }^{2}$ Department of Chemical Engineering, \\ Texas A\&M University, \\ College Station, TX 77843 \\ ${ }^{3}$ Department of Physics, \\ University of Texas at Austin, \\ Austin, TX 78712 \\ *kleung@sandia.gov
}

(Dated: January 20, 2014)

\begin{abstract}
Fluoroethylene carbonate (FEC) shows promise as an electrolyte additive for improving passivating solid-electrolyte interphase (SEI) films on silicon anodes used in lithium ion batteries (LIB). We apply density functional theory (DFT), ab initio molecular dynamics (AIMD), and quantum chemistry techniques to examine excess-electron-induced FEC molecular decomposition mechanisms that lead to FEC-modified SEI. We consider one- and two-electron reactions using cluster models and explicit interfaces between liquid electrolyte and model $\mathrm{Li}_{x} \mathrm{Si}_{y}$ surfaces, respectively. FEC is found to exhibit more varied reaction pathways than unsubstituted ethylene carbonate. The initial bond-breaking events and products of one- and two-electron reactions are qualitatively similar, with a fluoride ion detached in both cases. However, most one-electron products are chargeneutral, not anionic, and may not coalesce to form effective $\mathrm{Li}^{+}$-conducting SEI unless they are further reduced or take part in other reactions. The implications of these reactions to silicon-anode based LIB are discussed.
\end{abstract}




\section{INTRODUCTION}

Solid-electrolyte interphase (SEI) films that passivate low voltage anode surfaces are important for lithium ion battery operations. 1 - ${ }^{-5}$ These films arise from electrochemical reduction and subsequent breakdown of the organic solvent-based electrolyte, which is unstable under battery charging potentials. With the correct choice of electrolyte, stable SEI films are formed, blocking further electron transfer from the anode to the electrolyte, yet permitting lithium $\left(\mathrm{Li}^{+}\right)$transport. Small amounts of additives are often added to the electrolyte to modify the structure and performance of SEI films.

Additives may be particularly important for the next generation of anode battery materials like silicon $(\mathrm{Si})$, tin, and other alloys. For example, Si promises much higher lithium ion capacities than commercially used graphite anodes. ${ }^{[6}$ However, Si exhibits large volumetric expansion during $\mathrm{Li}$ intercalation. This often results in cracking, leading to detachment of particles from each other $\frac{788}{78}$ and perhaps from SEI films formed during previous cycles. There appears to be a need to continuously reform the SEI layer after each cycle, leading to consumption of $\mathrm{Li}^{+}$. Thus, in general, Si anodes have not been sufficiently stable over hundreds of charge/discharge cycles to be useful for commercial automobile batteries. SEI films on traditional graphite anodes yield less capacity fade, even though chemical compositions of SEI films on the two materials appear similar. 9

Recently, fluoroethylene carbonate (FEC, Fig. 17) was found to improve the cycling be-

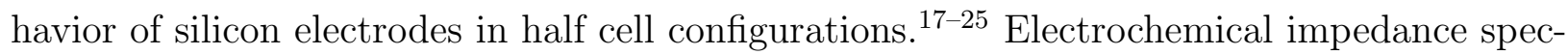
troscopy revealed that FEC-modified SEI films on $\mathrm{Si}$ yield lower $\mathrm{Li}^{+}$transfer resistance, while atomic force microscopy reported smoother SEI surfaces. Mass spectroscopy and Fourier transform infrared spectroscopy techniques showed little evidence of C-F covalentlybonded motifs in the SEI layers. Beyond these broad areas of agreement, details of SEI structure and composition reported by different groups differed. There are discrepancies regarding whether FEC increases the film thickness and LiF composition, and regarding whether FEC and vinylene carbonate (VC) have similar additive effects. Oxalate ${ }^{18120}$ and polycarbonate $\sqrt{18} \sqrt[20 \mid 22]{ }$ SEI components are reported in some studies, but not others.

Closely related to SEI chemical composition is the chemical mechanisms responsible for decomposition of FEC. The sequence of covalent bond breaking, the propagation of reaction intermediates to form polymeric products (if any), and the number of electrons transferred to 
reacting complexes at each stage have not been elucidated experimentally. ${ }^{26 \mid}$ The apparent absence of C-F bonds in the SEI has prompted at least one experimental work to speculate that volatile fluorine-containing hydrocarbon components like $\mathrm{C}_{2} \mathrm{H}_{3} \mathrm{~F}$ are removed as gas products before they can form SEI films. ${ }^{29}$ Another proposed mechanism involves the elimination of hydrogen fluoride (HF) from FEC to form vinylene carbonate (VC) deriviatives. $\stackrel{30}{30}$ Others have disputed this claim, citing observed differences between FEC- and VC-derived SEI films. 20

Electronic structure modeling is an excellent complement to experimental analysis $\underline{28 \mid 31}\lfloor\underline{43}$ While unlikely to yield the entire sequence of reactions and precise product branching ratios, modeling is useful for interrogating whether each proposed bond-breaking/making step is exothermic, has a sufficiently low free energy barrier, or whether it will be superceded by other reaction pathways. Concerns about theoretical accuracy can be alleviated by using multiple density functional theory (DFT) and quantum chemistry methods to crosscheck predictions. The role of electrode surfaces in promoting/hindering SEI film formation reactions can also be elucidated. Many insightful and evocative modeling works on bare

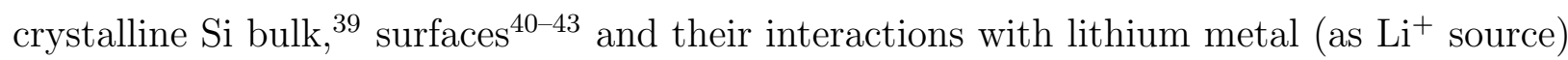
have been published, but so far they have not focused on SEI formation mechanisms. The Si models used in these works also tend to be bare Si surfaces, which can exist only under ultrahigh vacuum (UHV), not electrochemical, conditions.

Our modeling effort focuses on the initial steps of FEC decomposition, disputes the HF and $\mathrm{CH}_{2} \mathrm{CHF}$ reaction pathways proposed in the literature, and reveals lower barrier reaction mechanisms. Our work also explores subsequent SEI-formation steps that can occur. The two types of model used here dovetails with the two regimes of SEI film formation widely associated with EC/dimethyl carbonate (DMC) mixtures on graphite anodes and freshly cut metal surfaces. $\frac{21328}{2}$ The initial step consists of fast, two-electron attack; the later stage involves one-electron reduction of solvent or salt molecules. The latter dominates when electron tunneling/transfer through the half-formed SEI layer slows down. This two-stage mechanism may be consistent with the two-layer SEI structure revealed in experiments. An inorganic inner layer conducting $\mathrm{Li}^{+}$but blocking solvent and $e^{-}$transport, and an outer porous organic layer penetrable by solvent molecules, have been demonstrated $[44[46$ Note that as-formed SEI films may further undergo chemical/electrochemical evolution during cycling. 
To model two- $e^{-}$reactions, we use $\mathrm{Li}_{13} \mathrm{Si}_{4}$ model anodes with their (010) surfaces in direct contact with a liquid mixture of FEC and EC. This surface is meant as a prototype to study the fast, two- $e^{-}$electron transfer regime. It is meant to mimic battery charging-induced Si cracking events that expose SEI-free surfaces to the electrolyte. This can take place during the initial or subsequent charge cycles. The anode stochiometry is chosen to represent one of the strongly lithiated Li-Si crystalline phases, $\stackrel{47}{ }$ which are in turn models for disordered Li-Si alloys in cycled materials. Unlike the more commonly studied $\mathrm{Li}_{15} \mathrm{Si}_{4}$ stoichiometry, the orthonormal unit cell of crystalline $\mathrm{Li}_{13} \mathrm{Si}_{4}$ exhibits three unequal lattice constants. This inequality facilitates lattice-matching to model oxide films on anode surfaces. Rapid FEC decomposition induced by two $e^{-}$transfer is observed. One-electron decomposition of FEC is examined using cluster-plus-dielectric models in the absence of the silicon electrode. Such calculations were pioneered by Balbuena and coworkers and are valid for reactions that take place in the bulk liquid region. $31+33$

We also address the role played by silicon oxide. Theoretical studies of silica and related oxides in the context of lithium-ion batteries have been conducted, 480 but SEI film formation reactions on those surfaces were not a focus. It may be argued that silicon anodes should qualitatively differ from graphite with respect to initial SEI formation. Unlike graphite, silicon samples are generally covered with a native oxide layer about $20 \AA$ thick. Recent work demonstrated that SEI films on cycled silicon anodes contains buried $\mathrm{SiO}_{2}$ and/or lithium silicate derived from $\mathrm{SiO}_{2}$. 51 This dense oxide/silicate insulating layer may slow down $e^{-}$ transfer sufficiently during initial charging that the two-electron regime entirely vanishes. .52 Therefore a computational model that includes an electrode as well as a passivation oxide layer is also considered.

This paper is organized as follows. Section 2 briefly describes the computational methods. FEC decompositions induced by two- and one-electron injections are described in Sec. 3 and Sec. 4, respectively. Sec. 5 discusses the implications of our findings for SEI compositions and provides comparisons with experiments, and Sec. 6 concludes the paper with a brief summary. Two appendices examine the reductive decomposition of FEC adsorbed on lithium and silicon clusters using hybrid DFT functionals, and report two-electron mechanisms similar to those described in the main text. 


\section{METHODS}

Finite temperature $a b$ initio molecular dynamics (AIMD) simulations are conducted under solvent-immersed electrode conditions to study two-electron-induced FEC decomposition. These calculations are performed using the Vienna Atomic Simulation Package (VASP) version $4.6^{53 \mid 54}$ and the PBE density functional. ${ }^{[5]}$ A $400 \mathrm{eV}$ planewave energy cutoff and a $10^{-6} \mathrm{eV}$ convergence criterion is applied at each Born-Oppenheimer time step. Tritium masses on EC are substituted for protons to permit a time step of $1 \mathrm{fs}$. The trajectories are kept at an average temperature of $\mathrm{T}=450 \mathrm{~K}$ using Nose thermostats. The elevated temperature reflects the need to "melt" EC, which has an experimental freezing point above room temperature, and to improve sampling efficiency ${ }^{[56}$ In real batteries DMC cosolvent molecules reduce the viscosity, but DMC is not included herein. As a result, bond-breaking reactions observed in this work reflects accelerated kinetics pertinent to $\mathrm{T}=450 \mathrm{~K}$.

Several types of simulation cells are considered. One has dimensions $15.84 \times 33.00 \times 13.32 \AA^{3}$ and contains an apolar $\mathrm{Li}_{156} \mathrm{Si}_{48}$ slab with a zero dipole moment perpendicular to the exposed (010) surfaces. The bulk $\mathrm{Li}_{13} \mathrm{Si}_{4}$ structure is taken from Ref. 47. For that system, the (010) surface is found to be among the lowest energy

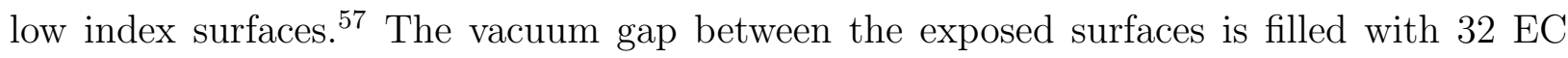
molecules, which are pre-equilibrated using Monte Carlo simulations with the Towhee Monte Carlo code, and simple molecular force fields described in earlier works. ${ }^{[5859}$ Then 8 of the 32 EC molecules at the electrode surfaces are replaced with FEC and Monte Carlo is resumed for 5000 passes. This spatial distribution of molecules faciliates FEC decomposition over EC. Finally, AIMD is initiated using $2 \times 1 \times 2$-point Brillouin zone sampling. During experimental preparation of battery cells, the voltage is lowered slowly. The higher reductive potentials of additives mean that they are first decomposed before other electrolyte components are reduced. (See however Ref. 60 for an alternate interpretation.) Strict voltage control is lacking in these AIMD simulations, $\frac{61}{6}$ wich are meant to mimic post- $\mathrm{Li}_{x} \mathrm{Si}_{y}$ cracking during cycling conditions, not electrode preparation. Thus, we have used spatial variations in additive compositions to enhance preferential FEC decomposition. In VASP calculations, the Bader decomposition technique is applied to determine the net charge on FEC fragments. 62

Another simulation cell has the same Li-Si alloy anode and liquid electrolyte, but in- 
cludes $\mathrm{a} \sim 7 \AA$ thin, stoichiometric $\mathrm{Li}_{4} \mathrm{SiO}_{4}$ layer on each electrode surface. Each oxide film amounts to a bilayer of $\mathrm{SiO}_{4}^{4-}$ units surrounded by $\mathrm{Li}^{+}$ions. The cell dimensions are $15.84 \times 44.40 \times 13.32 \AA^{3}$. Details about this oxide-covered model anode will be discussed in future publications.

Finally, we consider an AIMD trajectory without an electrode. $31 \mathrm{EC}, 1 \mathrm{FEC}, 1 \mathrm{Li}^{+}$, and an excess electron reside in this $(15.24 \AA)^{3}$ simulation cell. A liquid cell configuration of $32 \mathrm{EC}$ and $\mathrm{Li}^{+}$is taken from Ref. 58. One EC coordinated to $\mathrm{Li}^{+}$is replaced by an FEC molecule which is deformed into a geometry that resembles an $\mathrm{FEC}^{-}$(see the Results sections below), and then an $e^{-}$is added. When AIMD is initiated from this configuration, the excess $e^{-}$is found to be successfully localized on the FEC molecule.

Static cluster-based, static optimization calculations apply DFT/PBE and Möller-Plesset second order perturbation (MP2) in conjunction with the Gaussian (G09) suite of programs 63 and the "smd" dielectric continuum approximation $[64$ The dielectric constant $\epsilon$ is set to 40, which approximates the environment of the entire battery electrolyte, not just liquid EC. Geometry optimization is performed using the $6-31+G(d, p)$ basis set. Single point energies are computed at the $6-311++G(3 d f, 2 p d)$ level of theory. Vibrational frequencies are calculated for stable structures and transition states using the smaller basis, yielding zero point energies and thermal corrections to electronic energies. The DFT/PBE functional is chosen to complement AIMD/PBE simulations in this work, and the MP2 method is picked to be consistent with MP2 calculations in one of the authors' previous work ${ }^{28}$ and other modeling effort in the literature $\stackrel{3435}{B}$ Both $(\mathrm{EC})_{2} \mathrm{FEC}^{-}: \mathrm{Li}^{+}$and $\mathrm{FEC}^{-}: \mathrm{Li}^{+}$clusters are considered. The larger cluster is chosen to reflect a previous AIMD prediction that $\mathrm{Li}^{+}$is coordinated to slightly more than 3 EC molecules in EC liquid if one EC contains an excess electron. $\underline{58}$

Hybrid DFT functionals ${ }^{65} 67$ are used for studies of FEC:Li ${ }_{50}$ and FEC:Li ${ }^{+} \mathrm{Si}_{16} \mathrm{H}_{15} \mathrm{clus}^{-}$ ters. The results are described in the appendices. 


\section{RESULTS: TWO-ELECTRON MECHANISM}

\section{A. Pristine Electrodes}

We first consider unbiased AIMD simulations of liquid electrolyte in contact with the (010) surfaces of a $\mathrm{Li}_{13} \mathrm{Si}_{4}$ slab. Figs. 1 $\mathrm{d}$ and $1 \mathrm{p}$ depict snapshots at the $t=0$ and $t=$ 4 ps points of an AIMD trajectory. On the upper surface of Fig. 1p, three FEC molecules have spontaneously absorbed two $e^{-}$from the electrode, each breaking first one $\mathrm{C}_{\mathrm{C}}-\mathrm{O}_{1}$ or $\mathrm{C}_{\mathrm{C}^{-}} \mathrm{O}_{2}$ bond and then the other (two are shown in Fig. 1 1 ). An $\mathrm{F}^{-}$anion is ejected almost simultaneously. This leaves $\mathrm{CO}, \mathrm{F}^{-}$, and $\mathrm{C}_{2} \mathrm{H}_{3} \mathrm{O}_{2}^{-}$as products. Fig. 1 $1 \mathrm{~b}$ zooms in on these fragments. In one of them, a $\mathrm{C}-\mathrm{H}$ bond has also cleaved, releasing a hydrogen atom that becomes a $\mathrm{H}^{-}$bound to a $\mathrm{Si}$ atom on the anode surface (Fig. 1b). Even in this case, the product cannot be considered "HF." On the bottom surface (Fig. 1p), a $\mathrm{F}^{-}$is ejected before any other bond breaking occurs. The resulting $\mathrm{C}_{3} \mathrm{H}_{3} \mathrm{O}_{3}^{-}$anion then initiates nucleophilic attack on the $\mathrm{C}_{\mathrm{C}}$ atom of a neighboring intact EC molecule (see Fig. 1p for details). This may be the initiation of oligomer formation. No $\mathrm{HF}$ or $\mathrm{CH}_{2} \mathrm{CHF}$ is released, contrary to mechanisms proposed in the literature ${ }^{29130} \mathrm{By}$ the nature of the simulation, the decomposition reactions observed are not imposed by any assumption, but are the natural manifestations of low-barrier mechanisms.

Along this trajectory, after another $5.6 \mathrm{ps}$, two EC and another FEC molecule on the surfaces decompose (not shown). The two EC molecules absorb two $e^{-}$each to form $\mathrm{CO} / \mathrm{C}_{2} \mathrm{H}_{4} \mathrm{O}_{2}^{2-}$ and $\mathrm{C}_{2} \mathrm{H}_{4} / \mathrm{CO}_{3}^{2-}$, as has been observed on $\mathrm{Li}^{+}$intercalated graphite edges. 58 The newly reacting FEC forms $\mathrm{CO}, \mathrm{C}_{2} \mathrm{H}_{3} \mathrm{O}_{2}^{-}$, and $\mathrm{F}^{-}$, the majority product in Fig. 1 1 . No further dimerized product is observed. While we have only considered one AIMD trajectory with a single initial, force-field pre-equilibrated configuration, the multiple bond-breaking events observed, to some extent, serve as a reasonable sized sample of chemical reactions. The majority of FEC molecules, upon accepting two $e^{-}$, react to form $\mathrm{CO}$ and $\mathrm{F}^{-}$.

On the whole, these FEC $+2 e^{-}$reactions yield more varied products/intermediates than $\mathrm{EC}^{2-}$ breakdown. ${ }^{28}$ Simulations of FEC reduction on a lithium cluster and cluster models of weakly-lithiated Si surfaces (appendices A and B) show that $\mathrm{C}_{\mathrm{C}^{-}} \mathrm{O}$ bond breakings via 2 $e^{-}$mechanisms are also thermodynamically and kinetically favorable, facilitated by multiple bindings with the surface. Other products, including Si-C bonded motifs, are observed if a 
different electrode stochiometry is used in AIMD simulations (see Ref. 57 for details).

Among the fragments observed on these $\mathrm{Li}_{13} \mathrm{Si}_{4}$ surfaces, $\mathrm{F}^{-}$should precipitate with $\mathrm{Li}^{+}$ to form $\mathrm{LiF}(\mathrm{s})$, which is a part of the SEI. The $\mathrm{R}_{-} \mathrm{CHO}^{-}$functional groups of the organic anionic fragments (Fig. 1b) are reactive and may participate in further nucleophilic attacks on intact solvent molecules, like the $2-e^{-}$decomposition products of EC $\stackrel{28}{{ }^{28}}$ Unlike $2-e^{-}$attack

on $\mathrm{EC},{ }^{28 \mid 31} \mathrm{CO}_{3}^{2-}$ formation is not observed. Appendix $\mathrm{B}$ also shows that a $2-e^{-}$induced $\mathrm{CO}_{3}^{2-}$-releasing FEC reaction is exothermic but exhibits a high barrier when computed on a Si-cluster. Unlike $\mathrm{EC}^{2-}, 28$ we have been unable to stabilize intact $\mathrm{FEC}^{2-}$ molecular structures in a cluster geometry. $\mathrm{FEC}^{2-}: \mathrm{Li}^{+}$complexes always spontaneously decomposes, whether a dielectric continuum treatment is used or not. Hence no cluster-based calculation of $\mathrm{FEC}^{2-}$ bond-breaking barrier/reduction potential or direct comparison with AIMD/PBE reaction timescales following $2-e^{-}$reduction of intact FEC molecules can be made.

\section{B. Attempt at Modeling One- $e^{-}$Mechanisms on Oxide-Covered Electrodes}

We have made a preliminary attempt at modeling $1-e^{-}$attacks on FEC in the presence of a $\mathrm{Li}_{13} \mathrm{Si}_{4}$ electrode, with each surface coated with a $7 \AA$ thick $\mathrm{Li}_{4} \mathrm{SiO}_{4}$ layer so that the FEC liquid is no longer in contact with $\mathrm{Li}_{13} \mathrm{Si}_{4}$ surfaces (Fig. 1f). Two FEC are decompose in picosecond time scales. Despite the expectation that the oxide should slow down electron transfer and enhance 1- $e^{-}$attack on FEC over 2- $e^{-}$reduction, Bader charge decomposition analysis shows that the products are still consistent with $2-e^{-}$-induced reactions.

The reason for $2-e^{-}$attack may be twofold. (1) The reduction potentials may favor double reduction of FEC, as in the case for EC. ${ }^{28}$ The proximity of the metallic electrode means that the dielectric constant at high frequencies remains large. High $\epsilon_{\infty}$ means that reorganization energies for both one and two $e^{-}$transfer to FEC may be low, and therefore electron transfer through the oxide is fast. If that is indeed the case, two electron attack is the correct prediction. (2) However, AIMD/PBE overestimates $e^{-}$tunneling rate due to DFT/PBE delocalization errors. This tendency has been discussed in Ref. 59. Thus, $2-e^{-}$attack on oxide-covered anode may be an incorrect DFT prediction. Hybrid DFT functionals, less susceptible to DFT delocalization errors, may be used to study this system in the future, although they are costly to use in the periodically replicated simulation cells discussed in this section. In the next sections, 1- $e^{-}$mechanisms are imposed by adding one 
excess $e^{-}$to model systems in the absence of an electrode.

\section{RESULTS: ONE-ELECTRON MECHANISMS}

\section{A. AIMD simulations in bulk liquid}

An AIMD trajectory of $31 \mathrm{EC}, 1 \mathrm{FEC}, 1 \mathrm{Li}^{+}$, and an excess $e^{-}$in the simulation cell is considered next. By design, the excess $e^{-}$resides on the FEC molecule which is coordinated to the $\mathrm{Li}^{+}$, as discussed in Sec. II. After $5.3 \mathrm{ps}$, the initially intact $\mathrm{FEC}^{-}$breaks a $\mathrm{C}_{\mathrm{C}^{-}}$ $\mathrm{O}_{1}$ bond, similar to the initial reaction step observed in most reactions on $\mathrm{Li}_{13} \mathrm{Si}_{4} \mathrm{surfaces}$ (Fig. 17). A snapshot of this configuration is shown in Fig. 2. Using a different forcefield pre-equilibrated initial configuration, the same bond breaks after 16.0 ps (not shown). The bond-breaking time scales are slightly different due to the stochastic nature of barrier crossing events. Intuitively, $\mathrm{C}_{\mathrm{C}}-\mathrm{O}_{1}$ bond-breaking should be favored over $\mathrm{C}_{\mathrm{C}^{-}}-\mathrm{O}_{2}$ because the electron-withdrawing F-atom should stabilize the - $\mathrm{CHFO}_{1}^{-}$group. Unlike two-electroninduced reactions described in the previous section, the $\mathrm{C}-\mathrm{F}$ bond has not broken and the $\mathrm{F}^{-}$has not yet detached from the $\mathrm{FEC}^{-}$in this trajectory. The reason for the intact $\mathrm{C}-\mathrm{F}$ bond may be the lack of $\mathrm{Li}^{+}$in the proximity to abstract $\mathrm{F}^{-}$and form a stable LiF cluster. This point will be reiterated in light of cluster-based calculations described below.

\section{B. Cluster Calculations: Intact FEC $^{-}$}

Cluster-based predictions are depicted in Figs. 3.6. First we consider the geometries of metastable $\mathrm{FEC}^{-}: \mathrm{Li}^{+}$complexes prior to bond-breaking events. Configurations A-D (Fig. $3 \mathrm{a}-\mathrm{d}$ ) are somewhat analogous to the $\mathrm{EC}^{-}: \mathrm{Li}^{+}$geometry. ${ }^{31}$ The $\mathrm{C}_{\mathrm{C}^{-}} \mathrm{O}_{\mathrm{C}}$ bond is bent out of the plane containing the 5-atom ring, like $\mathrm{EC}^{-}$, but unlike charge neutral FEC or $\mathrm{EC}$, because the $\mathrm{C}_{\mathrm{C}}$ atom is now $\mathrm{sp}^{3}$ (or " $\mathrm{sp}^{2.5 ")}$ ) hybridized to accommodate an extra $e^{-}$. Unlike the more symmetric $\mathrm{EC}^{-}: \mathrm{Li}^{+}$, complex, there are four distinct binding geometries depending on whether $\mathrm{Li}^{+}$and $\mathrm{F}$ reside in the same or opposite side of the 5-member ring, and whether they are on the same side of the bisecting plane perpendicular to the ring.

Another configuration, E (Fig. 3p), finds $\mathrm{Li}^{+}$residing on the approximate bisector plane, only coordinated to $\mathrm{O}_{\mathrm{C}}$. All 5 configurations are close in energy, within $0.065 \mathrm{eV}(0.042 \mathrm{eV})$ of 
each other depending on whether MP2 (PBE) is used (Table ??). Configuration A (Fig. 3 a) is most stable according to the PBE functional. When MP2 is used, it is more stable than all other complexes except D (Fig. 3d) by a small $0.020 \mathrm{eV}$, which is within thermal energy of the MP2-predicted global minimum.

Given the fact that neither DFT nor MP2 has attained chemical accuracy (i.e., a mean error of less than $\sim 0.04 \mathrm{eV}$ compared to experiments), we will henceforth use $\mathbf{A}$ as the starting configuration of all further cluster-based degradation studies. The most important metrics are the barrier heights measured against the most stable intact $\mathrm{FEC}^{-}$configuration. A small uncertainty of $\sim 0.02 \mathrm{eV}$ in the energy of the starting, unreacted complex merely adds a small amount to barrier heights and does not change the qualitative conclusions.

Using Configuration A to represent $\mathrm{FEC}^{-}: \mathrm{Li}^{+}$, the predicted MP2 reduction potential of FEC: $\mathrm{Li}^{+}$is $0.75 \mathrm{~V}$, which is $0.22 \mathrm{~V}$ higher than that of $\mathrm{EC}: \mathrm{Li}^{+}$based on a previous study at the same level of theory. ${ }^{28}$ This difference indicates that $\mathrm{FEC}: \mathrm{Li}^{+}$accepts an electron at higher voltages than $\mathrm{EC}: \mathrm{Li}^{+}$. The experimental value appears to be $\sim 0.95 \mathrm{~V} \underline{68} \mathrm{As}$ mentioned above, adding a second $e^{-}$to the $\mathrm{FEC}^{-}: \mathrm{Li}^{+}$cluster leads to immediate decomposition, and thus the reduction potential of intact $\mathrm{FEC}^{-}$cannot be computed.

If the dielectric continuum approximation is omitted, the $\mathrm{C}_{\mathrm{C}^{-}}-\mathrm{O}_{1}$ bond in $\mathbf{A}$ spontaneously breaks during geometry optimization regardless of whether PBE or MP2 is used. The resulting structure is similar to $\mathbf{F}$ (Fig. 3F, which is however optimized with a dielectric approximation, not in the gas phase). Recall that the same bond spontaneously breaks in AIMD simulations (Fig. 2). The same bond also breaks in $\mathbf{C}$ and $\mathbf{D}$ in the gas phase (no dielectric) during PBE optimization, while the $\mathrm{C}_{\mathrm{C}}-\mathrm{O}_{2}$ bond does not. The next section focuses on decomposition initiated by $\mathrm{C}_{\mathrm{C}}-\mathrm{O}_{1}$ bond-breaking.

\section{Cluster Calculations: Proposed FEC $^{-}$Decomposition Mechanisms}

This subsection shows that the most probable (one-eletron) $\mathrm{FEC}^{-}$decomposition route is an indirect, multi-step reaction leading to removal of an $\mathrm{F}^{-}$anion followed by release of $\mathrm{CO}_{2}$ and an organic radical.

Bond-breaking barriers computed using the $\mathrm{FEC}^{-}: \mathrm{Li}^{+}$cluster are listed in Table ??, and the global free energy landscape is illustrated in Fig. 5. $\mathrm{C}_{\mathrm{C}}-\mathrm{O}_{1}$ cleavage yields the lowest initial bond-breaking barrier, predicted using the MP2 (PBE) method to be $0.26 \mathrm{eV}$ 
$(0.23 \mathrm{eV})$. This forms intermediate $\mathbf{F}$ (Fig. $3 \mathrm{f}$ ) which is metastable by $0.09 \mathrm{eV}$ (stable by $-0.11 \mathrm{eV})$. The small $(\sim 0.1 \mathrm{eV})$ discrepancies between MP2 and PBE barriers indicate that these reactions should be fast regardless of computational methods. A fast reaction rate is qualitatively consistent with the AIMD trajectory (Fig. 2 showing $\mathrm{C}_{\mathrm{C}}-\mathrm{O}_{1}$ bond-breaking within picoseconds.

Next we consider possible subsequent steps. Guided by $2-e^{-}$reactions (Fig. 1p), we next examine C-F bond cleavage that proceeds from $\mathbf{F}$ to $\mathbf{G}$ (Fig. 4a). MP2 calculations reveal that the reaction is exothermic by $0.55 \mathrm{eV}$ (or $0.64 \mathrm{eV}$ measured from the starting structure A, Table ??). The barrier from $\mathbf{F}$ to $\mathbf{G}$ is very small (0.12 eV, Table ??). (Using $\mathbf{F}$ as reference implies that $\mathbf{F}$ is sufficiently thermalized following bond-breaking reaction from A.) The corresponding PBE values are $0.45 \mathrm{eV}, 0.34 \mathrm{eV}$, and $0.26 \mathrm{eV}$, respectively. Hence the same two-step reaction seen in a majority of two-electron reactions (Fig. 1 $1 \mathrm{~b}$ ) is also thermodynamically and kinetically viable for singly reduced FEC. Compared with the AIMD simulations depicted in Fig. 2, the reason the C-F bond remains intact there seems to have mostly entropic origins. The lone $\mathrm{Li}^{+}$ion is far removed from the F atom in Fig. 2, and a longer trajectory appears necessary for $\mathrm{Li}^{+}$to diffuse to and coordinate with the fluorine atom so the latter can detach from the $\mathrm{FEC}^{-}$fragment.

Due to the reactive nature of partially decomposed $\mathrm{FEC}^{-}$, numerous product channels and transition states exist for subsequent steps. In some cases the $\mathrm{Li}^{+}$and/or detached $\mathrm{F}^{-}$ ions are omitted to assist calculation of the specific barriers. These models mimic conditions such that $\mathrm{Li}^{+}$and/or $\mathrm{F}^{-}$have "diffused away."

We next remove $\mathrm{Li}^{+}$and $\mathrm{F}^{-}$from $\mathbf{G}$ and reoptimize the geometry to $\mathbf{H}$. The configuration shown in Fig. 4b is the most stable among several conformations separated by low rotational barriers. Our attempt to initiate attack on either the $\mathrm{C}_{\mathrm{C}}$ or $\mathrm{C}_{\mathrm{E}}$ atom of an intact $\mathrm{EC}$ molecule with the $\mathrm{C}$ or $\mathrm{O}$ atom of $\mathbf{H}$ leads to endothermic reactions with substantial barriers.

Unimolecular reactions exhibit much lower barriers and are much more exothermic. Breaking the $\mathrm{C}_{\mathrm{E}}-\mathrm{O}_{2}$ bond of $\mathbf{H}$ to form $\mathrm{CO}_{2}$ and $\cdot \mathrm{CH} 2 \mathrm{CHO}$ (I, Fig. 4 barrier of $0.869(0.205) \mathrm{eV}$ and the most exothermic products found (Table ??, Fig. 5). A large discrepancy between MP2 and non-hybrid DFT $\mathrm{C}_{\mathrm{E}}-\mathrm{O}$ cleavage barriers is observed. A similar discrepancy has been documented for the gas phase $\mathrm{Li}^{+}: \mathrm{EC}^{-}$complex ${ }^{34}$ Compared to highly accurate $\operatorname{CCSD}(\mathrm{T})$ calculations, the barrier for breaking the $\mathrm{C}_{\mathrm{E}^{-}} \mathrm{O}$ bond in $\mathrm{EC}^{-}$is overestimated by $\sim 0.15 \mathrm{eV}$ when using MP2 and underestimated by BLYP by $\sim 0.33 \mathrm{eV} \underline{34}$ 
The hybrid B3LYP DFT functional, which gives predictions closer to the CCSD(T) method for $\mathrm{EC}^{-}$, predicts a more modest $0.392 \mathrm{eV}$ barrier for breaking this bond in FEC. Even the likely overestimated $\mathrm{MP} 2 \mathrm{C}_{\mathrm{E}}-\mathrm{O}$ cleavage barrier does not preclude the unimolecular reaction from occurring during battery charging time scales ( $<1$ hour) at room temperature.

Note that the free energy of $\mathbf{H}$ is referenced to cluster $\mathbf{A}$, which has a different number of atoms, via Configuration $\mathbf{J}$ (Fig. $4 \mathrm{~d}$ to be discussed below). $\mathbf{J}$ is optimized with and without $\mathrm{Li}^{+}$and $\mathrm{F}^{-}$; its free energy is assumed to be the same with or without these ions. Using this procedure, $\mathbf{G}$ (with $\mathrm{Li}^{+} / \mathrm{F}^{-}$) and $\mathbf{H}$ (without) are predicted to be similar in MP2 (PBE) free energy, within $0.19 \mathrm{eV}(0.03 \mathrm{eV})$ of each other. This level of agreement is acceptable for our purposes.

Depending on the rate of $e^{-}$transfer through the nascent SEI film and the concentration of intermediates, the radicals $\mathbf{F}$ and $\mathbf{G}$ may dimerize, or they may absorb extra $e^{-}$and participate in further reactions, like $\mathrm{EC}^{-}$and $\mathrm{EC}^{2-} \cdot 28$ Enumerating subsequent reactions that may involve redox steps is beyond the scope of this work. The implication of proposed alternate fates of FEC on SEI formation is re-examined in Sec. V.

$\mathrm{CO}$ elimination from $\mathbf{H}$ is predicted to be endothermic by 1.28 (1.36) eV when computed using the MP2 (PBE) method, and will not proceed.

\section{Cluster Calculations: Other Initiation Steps}

Again motivated by $2-e^{-}$reactions, we next consider the direct breaking of the $\mathrm{C}-\mathrm{F}$ in A to form the charge-neutral radical $\mathbf{J}$ with an intact 5-atom ring. According to PBE calculations, the reaction is exothermic by $1.18 \mathrm{eV}$ with a barrier of $0.614 \mathrm{eV}$. $\mathbf{J}$ can then undergo $\mathrm{C}_{\mathrm{E}}-\mathrm{O}_{2}$ bond breaking to yield $\mathrm{CO}_{2}$ and $\cdot \mathrm{CH}_{2} \mathrm{CHO}$ (I, discussed above; purple line in Fig. 5). This unimolecular reaction that releases $\mathrm{CO}_{2}$ is reminiscent of a VC-based reaction predicted in Ref. 60 for the reaction between $\mathrm{VC}$ and $\mathrm{EC}^{-}$. Unlike that case, $\mathrm{CO}_{2}$ is predicted to be a biproduct which accompanies the release of uncharged organic radicals that may not form effective SEI components. The PBE barrier assocated with the first step this route is much higher than the one examined in the last subsection (green line), and we have not computed the MP2 barriers associated with it. The final products are the same as in the last subsection. $\mathbf{J}$ can also be obtained from ring-reformation from $\mathbf{G}$; it can can potentially undergo polymerization reactions. $\stackrel{27}{.27}$ 
We have also considered the cleavage of the $\mathrm{C}_{\mathrm{E}}-\mathrm{O}_{2}$ bond in $\mathbf{A}$ to form $\mathbf{K}$ (Fig. 4 4 ). The barrier is found to be $0.927(0.408) \mathrm{eV}$ (orange line in Fig. 5). Unlike all other barriers considered so far, but analogous to breaking the same bond in the ring-opened radical (Table ??), the MP2 and PBE barriers differ significantly, as noted earlier. Even the likely underestimated PBE barrier listed here gives a values higher than breaking the $\mathrm{C}_{\mathrm{C}}-\mathrm{O}$ bond $(\mathbf{A} \rightarrow \mathbf{F})$, suggesting that $\mathrm{C}_{\mathrm{E}^{-}} \mathrm{O}$ bond cleavage is kinetically unfavorable in $\mathrm{FEC}^{-}$. (See also appendix B.) This $\mathbf{A} \rightarrow \mathbf{K}$ pathway is not further considered, but it may still occur if aided by the electrode surface. Breaking the $\mathrm{C}_{\mathrm{E}^{-}} \mathrm{O}_{1}$ bond is less exothermic; the barrier has not been computed because transition state searches have ended in the transition state that yields $\mathrm{C}_{\mathrm{E}^{-}} \mathrm{O}_{2}$ bond-breaking.

Elimination of $\mathrm{HF}$ from $\mathrm{FEC}^{-}$yields configuration $\mathbf{L}$ (Fig. $4 \mathrm{f}$ ) which is endothermic by $0.20 \mathrm{eV}(0.00 \mathrm{eV})$. No low barrier pathway for this two-bond-breaking reaction is found.

\section{E. Cluster Calculations: System Size Effect}

So far, the results are derived using a cluster with one FEC, plus a dielectric continuum that represents spectator solvent molecules. In experiments, the solvent is often a combination of EC and DMC, with FEC also present at low concentration. A more accurate way of representing the $\mathrm{FEC}^{-}: \mathrm{Li}^{+}$solvation shell is to introduce more molecules. Configurations M-P (Figs. 6a-d) depict optimized geometries when two extra EC are included in the $\mathrm{Li}^{+}$ coordination shell. Using the PBE functional, the most favorable intact FEC configuration $\mathbf{M}$ (Fig. 63) resembles the $\mathrm{FEC}^{-}: \mathrm{Li}^{+}$cluster $\mathbf{E}$ (Fig. 3p), where $\mathrm{Li}^{+}$only coordinates to one FEC $^{-}$O atom. $\mathbf{N}$ (Fig. 6b) is analogous to $\mathbf{A}$ (Fig. 3a) and is metastable, but by only $0.070 \mathrm{eV}$. In contrast, MP2 predicts that $\mathbf{M}$ and $\mathbf{N}$ are almost isoenergetic, emphasizing the somewhat sensitive dependence of their free energy ordering on computational methods and cluster size. Configuration $\mathbf{O}$ with a broken $\mathrm{C}_{\mathrm{C}}-\mathrm{O}$ bond (Fig. 6r) is analogous to configuration $\mathbf{F}$, but exhibits a lower exothermocity. $\mathbf{P}$ (Fig. 6 6 ) is similar to $\mathbf{G}$ (Fig. 泝) with a smaller release of free energy. $\mathbf{O}$ cannot be optimized using the MP2 method; it decomposes into $\mathbf{P}$ spontaneously.

We have not computed barriers using these larger clusters. Recall, however, that a $\mathrm{C}_{\mathrm{C}}-\mathrm{O}_{1}$ bond breaks within $5.3 \mathrm{ps}$ in AIMD/PBE simulations that treat all solvation molecules ex-

plicitly (Fig. 2). This timescale is consistent with at most a $0.1 \mathrm{eV}$ barrier. Thus, depending 
on the electronic structure method, cluster size, and treatment of temperature and out-lying spectator EC molecules, $\mathrm{C}_{\mathrm{C}}-\mathrm{O}_{1}$ bond breaking barriers vary from $\sim 0.1 \mathrm{eV}$ to a maximum of $0.26 \mathrm{eV}$. Such estimated barriers are consistent with $\mathrm{FEC}^{-}$lifetimes that are much shorter than battery charge/discharge timescales.

The main finding of this subsection is that using the smaller $\mathrm{Li}^{+}: \mathrm{FEC}^{-}$complex may slightly overestimate reaction exothermicities.

\section{DISCUSSIONS}

At least two requirements must be satisfied for good electrolyte additives: 1) they should react at voltages higher than electrolyte solvents/anions to ensure the SEI film is dominated by their breakdown products; 2) their reaction intermediates must also coalesce and/or further react to form SEI films that effectively transmit $\mathrm{Li}^{+}$ions but block solvent and electron transport. $\mathrm{Li}^{+}$-containing ionic solids made up of negatively charged species from additive/electrolyte decomposition are likely crucial for $\mathrm{Li}^{+}$transport. SEI made of purely charge-neutral oligomer products which do not contain $\mathrm{Li}^{+}$are unlikely to conduct $\mathrm{Li}^{+}$ efficiently, or for that matter become dense/compact enough to block solvent transport. Hence, both prediction of reduction potentials and elucidation of decomposition pathways are needed to define computational screening criteria that lead to design of better additives..$^{36}$

From this perspective, two-electron products $\left(\mathrm{F}^{-}\right.$and $\left.\mathrm{C}_{3} \mathrm{H}_{3} \mathrm{O}_{3}^{-}\right)$appear reasonable SEI components, although the latter contains $\mathrm{X}_{-} \mathrm{CHO}^{-}$groups that will likely undergo further reactions. Dimerization is observed; subsequent oligomerization may be possible. The most favorable sequence of one-electron reactions yields $\mathrm{F}^{-}$, uncharged radicals, and $\mathrm{CO}_{2}$. This suggests that the $1-\mathrm{e}^{-}$route yields $\mathrm{LiF}$, found in the SEI, and other uncharged organic products that, if they coaleasce, are likely neither very conductive to $\mathrm{Li}^{+}$nor form compact, effective SEI films. However, it cannot be ruled out that $\mathrm{CO}_{2}$ and $\mathrm{CHOCH}_{2}$. can be further reduced electrochemically and then become part of the SEI. Indeed, $\mathrm{CO}_{2}$ reduction may yield

oxalate $\left(\mathrm{C}_{2} \mathrm{O}_{4}{ }^{2-}\right)$, as reported in some measurements. $\frac{18 \mid 20}{1}$ The likelihood of these subsequent events should depend on the relative rates of electron transfer through the nascent SEI film and of preciptation/nucleation of charged fragments on the electrode surface.

Thus both 1- and 2-e mechanisms lead to rapid release of $\mathrm{F}^{-}$to form $\mathrm{LiF}$. We propose this is the main consequence of using FEC as additive. LiF can also arise from decomposition 
of $\mathrm{PF}_{6}^{-}$, which is often considered not to be an electrochemical reduction, but is related to $\mathrm{H}_{2} \mathrm{O}$ contamination. Hence FEC may generate LiF much more quickly.

Polycarbonates, suggested in some of the FEC/Si-anode literature, $\frac{18 / 20 \mid 22}{2 s}$ not directly observed in $\mathrm{FEC}^{n-}$ decomposition. A previous computational work by one of the authors proposed polycarbonate chain formation from two-electron reduction of ethylene carbonate (EC). Such chains are predicted to be unstable in high dielectric environments, their $\mathrm{ROCO}_{2} \mathrm{R}^{\prime}$ motifs as prone to electrochemical reduction and $\mathrm{C}_{\mathrm{C}^{-}} \mathrm{O}$ and $\mathrm{C}_{\mathrm{E}^{-}} \mathrm{O}$ cleavage as $\mathrm{EC}$ itself. However, if polycarbonate chains form large aggregates, the dielectric constant may be sufficiently lowered that they are no longer susceptible to excess $e^{-}$attacks. Thus polycarbonates cannot be ruled out even though the experimental evidence for their existence does not appear conclusive.

We have also performed preliminary calculations of $\mathrm{FEC}^{-}$decomposition on lithium silicate-covered electrode surfaces immersed in liquid electrolyte. This mixed oxide is known to be present after cycling silicon anodes in lithium ion batteries. The thin $(\sim 7 \AA)$ insulator oxide layers intervening between the metallic $\mathrm{Li}_{13} \mathrm{Si}_{4}$ and the electrolyte yield two-electron FEC decomposition reactions, and therefore appear not sufficiently thick to perform the necessary function of slowing down $e^{-}$transfer sufficiently to limit FEC decomposition to $1-e^{-}$reactions.

We have used PBE, MP2, and in one case, B3LYP methods to compute reaction barriers. In most cases the predictions are similar, within $\sim 0.1 \mathrm{eV}$ of each other. The exception is breaking of the $\mathrm{C}_{\mathrm{E}^{-}} \mathrm{O}$ bond, where $\mathrm{MP} 2(\mathrm{PBE})$ appears to overestimate (underestimate) the true barrier (see also appendix B).

\section{CONCLUSIONS}

In conclusion, we have examined the decomposition mechanisms of fluoroethylene carbonate (FEC), which is a promising additive for improving passivating solid electrolyte interphase (SEI) films on silicon anode surfaces in lithium ion batteries. Various mechanisms are examined using unconstrained AIMD simulations of explicit liquid electrolyte $/ \mathrm{Li}_{13} \mathrm{~S}_{4}$ interfaces and using cluster-based calculations. The two types of simulations are consistent with two- and one- $e^{-}$attack on FEC, respectively.

Multiple reaction products and pathways are observed in fast $2-e^{-}$induced FEC break- 
down. The main products are carbon monoxide or its precursor, $\mathrm{F}^{-}$anion, and negatively charged C- and O-containing fragments that may undergo further reactions. We also observe direct defluorination of " $\mathrm{FEC}^{2-}$," yielding a $\mathrm{C}_{3} \mathrm{H}_{3} \mathrm{O}_{3}^{-}$fragment with an intact 5-atom ring which in turn initiates nucleophilic attack on a neighboring $\mathrm{EC}$ molecule. $\mathrm{F}^{-}$can precipitate to form LiF, which has been shown to be abundantly present in FEC-derived SEI films, $17+24$ while the negatively charged organic fragments can also contribute to the $\mathrm{Li}^{+}$-conducting part of the SEI.

Similar initial bond-breaking routes and $\mathrm{F}^{-}$ion release are also found during $1-e^{-}$induced reactions. While reaction pathways and products have not been exhaustively enumerated, the first reaction is predicted to be the cleavage of the $\mathrm{C}_{\mathrm{C}}-\mathrm{O}_{1}$ bond regardless of whether unbiased AIMD/PBE simulation or cluster-based MP2/PBE barrier calculation is used. This internal consistency suggests that the predictions are reasonable. The most probable single $\mathrm{FEC}^{-}$molecule products are predicted to be $\mathrm{F}^{-}, \mathrm{CO}_{2}$, and $\mathrm{CHOCH}_{2} \cdot$ radicals. Future experiments can validate this prediction by analyzing the gas product composition. Neither $\mathrm{HF}$ nor $\mathrm{CHFCH}_{2}$, proposed in the literature, 29130 is found as a favorable reaction product or intermediate.

\section{Acknowledgement}

We thank Yang Liu and Louise Criscenti for useful discussions, and Yukihiro Okuno for sharing Ref. 60. Sandia National Laboratories is a multiprogram laboratory managed and operated by Sandia Corporation, a wholly owned subsidiary of Lockheed Martin Corporation, for the U.S. Department of Energy's National Nuclear Security Administration under contract DE-AC04-94AL85000. The work reported in the main text was supported by Nanostructures for Electrical Energy Storage (NEES), an Energy Frontier Research Center funded by the U.S. Department of Energy, Office of Science, Office of Basic Energy Sciences under Award Number DESC0001160. SB is funded by Sandia LDRD program. YM, JMM, and PBB were supported by the Assistant Secretary for Energy Efficiency and Renewable Energy, Office of Vehicle Technologies of the U. S. Department of Energy under Contract No. DE-AC02-05CH11231, Subcontract No. 7060634 under the Batteries for Advanced Transportation Technologies (BATT) Program. This research used resources of the

National Energy Research Scientific Computing Center, which is supported by the Office of 
Science of the U.S. Department of Energy under Contract No. DE-AC02-05CH11231.

\section{Appendix A: FEC on Li metal cluster}

To corroborate two-electron reduction pathways predicted in Sec. III A using hybrid DFT functionals, which are generally more accurate than the DFT/PBE method applied in the main text, an FEC molecule was placed on the (100) surface of a 50 atom face-centered cubic (FCC) Li cluster and optimized for 100 steps at the B3LYP/6-31G level of theory $65 \mid 66$ using the "smd" dielectric continuum approximation $(\epsilon=40)$. The cluster consisted of four layers of Li (Fig. 7a). The two bottom layers are frozen during the optimization to help maintain the bulk FCC structure.

Upon optimization, the FEC molecule decomposes on the surface. The initial and intermediate structures are shown in Fig. 7. The C-F bond stretches and the carbonyl oxygen migrates toward the surface (Step 20), causing the C-O bonds to break and form carbon monoxide (Step 40). The F atom dissociates and binds to the Li surface. These reaction features are characteristic of two- $e^{-}$attacks seen in DFT/PBE-based AIMD simulations (Fig. 17). In optimization step 80, the carbon monoxide fragment recombines with one of the $\mathrm{O}$ atoms of the remaining FEC fragment. In the final step, a reduced " $\mathrm{CO}_{2}$ molecule" forms, although the $\mathrm{C}_{\mathrm{E}^{-}} \mathrm{O}$ distance remains small $(1.61 \AA)$ and it may be argued that the $\mathrm{C}_{3} \mathrm{H}_{3} \mathrm{O}_{3}$ fragment is one entity. The last (100th) optimization step corresponds to the lowest energy structure found, with a root-mean-square error Cartesian force of 0.003 Hartrees/Bohr. F-containing solvent molecules for lithium air batteries have been predicted to react with lithium clusters in a similar way, by breaking C-F bonds after injection of electrons. ${ }^{71}$

\section{Appendix B: FEC on Si-cluster}

A cluster model of $\mathrm{Li}^{+}: \mathrm{Si}_{15} \mathrm{H}_{16}$ is employed to simulate the $\mathrm{Si}(100) 2 \times 1$ surface and to examine FEC reduction reactions on the surface. This model system might be relevant to silicon anodes with native oxide films etched away by HF gas treatment 11 The calculations

are performed using the Gaussian 09 suite of programs and hybrid B3PW91 functional.65|67 Previous studies have shown that B3PW91 is reliable for the open-shell species involved in the ethylene carbonate reduction reactions for lithium-ion batteries. ${ }^{3133}$ Both geome- 
try optimization and single-point calculations are carried out using a 6-311++G(d,p) basis set. Thermal corrections are included in the standard way, and analysis of atomic charges is generated using the CHelpG method $\frac{69}{6 h e}$ adsorption energy $E_{\text {ads }}$ is defined by $E_{\text {ads }}$ $=E_{\mathrm{sub} / \mathrm{ads}}-E_{\mathrm{sub}}-E_{\mathrm{ads}}$, in which $E_{\mathrm{sub} / \mathrm{ads}}$ is the total energy of the optimized substrateadsorbate structures, $E_{\text {sub }}$ is the energy of the substrate, and $E_{\text {ads }}$ is the energy of adsorbate. The $\mathrm{Li}^{+}: \mathrm{Si}_{15} \mathrm{H}_{16}$ substrate will be discussed in detail in a future publication. ${ }^{70}$ No dielectric continuum approximation is used in this appendix, and the reactions are therefore studied under ultra-high vacuum conditions.

As discussed in the main text, both one-electron and two-electron mechanisms are possible for decomposition of FEC. We first examine FEC adsorption on the optimized $\mathrm{Si}_{15} \mathrm{H}_{16}-\mathrm{Li}^{+}$ cluster. Three FEC adsorption modes are identified, as illustrated in Fig. 8. The major binding site is the carbonyl $\mathrm{O}\left(\mathrm{O}_{\mathrm{C}}\right)$ and the $\mathrm{Li}^{+}$in Configurations $\mathbf{1}$ and $\mathbf{2}$. $\mathbf{1}$ and $\mathbf{2}$ share similar geometries, and the only difference is the position of the $\mathrm{F}$ atom: one is toward the $\mathrm{Si}(001)$ surface, whereas the other is away from the surface. Not surprisingly, the DFT calculation indicates that the two configurations possess approximately the same adsorption energy $\left(E_{\text {ads }}=-1.14 \mathrm{eV}\right)$. Two binding sites are observed in Configuration 3: one is between the $\mathrm{F}$ atom and the $\mathrm{Li}^{+}$, and the other is between $\mathrm{O}_{\mathrm{C}}$ and a surface $\mathrm{Si}$ atom. The FEC adsorption is slightly weaker than that in $\mathbf{1}$ and $\mathbf{2}$, with an adsorption energy of $-0.93 \mathrm{eV}$, suggesting that the $\mathrm{O}_{\mathrm{C}}-\mathrm{Li}^{+}$interaction is stronger than $\mathrm{F}_{-}-\mathrm{Li}^{+}$. The FEC geometry shows little change in the adsorbed structures.

The FEC-Li ${ }^{+}-\mathrm{Si}_{15} \mathrm{H}_{16}$ cluster may receive one or two electrons before decomposition takes place, depending on the reduction potential, applied voltage, and electron transfer rate. Our geometry optimization produces 7 stable structures for the one-electron transfer process. The most stable one, $\mathbf{4}$, is obtained by adding an electron to and optimizing from Configuration $\mathbf{2}$, and the electron affinity (EA) is $-5.46 \mathrm{eV}$. The geometry of the FEC molecule is hardly changed in the process, implying no significant electron structure change of the adsorbed molecule. This is further verified by charge distribution analysis: most negative charge ( $\sim 87 \%$ ) fluxes into the $\mathrm{Si}_{15} \mathrm{H}_{16}$ cluster, whereas the charge on the FEC molecule remains roughly unchanged, as listed in Table ??. Thus, without the dielectric environment provided by the liquid electrolyte, the $\mathrm{Si}_{15} \mathrm{H}_{16}$ cluster retains most of the negative charge, retarding FEC decomposition.

Two-electron transfer reactions are also investigated and five stable structures are ob- 
tained after geometry optimization. The energetically most favorable structure is $\mathbf{5}$ generated by $\mathbf{1}+2 e^{-} \rightarrow \mathbf{5}$ (combined first and second $\mathrm{EA}=-7.99 \mathrm{eV}$ ). The overall configuration of $\mathbf{5}$ differs substantially from $\mathbf{1}$, in which the FEC molecule is away from the cluster and the ring plane is approximately perpendicular to the Si surface. The ring resides on the top of the cluster and is parallel to the $\mathrm{Si}(001)$ surface in Configuration 5. Another stable structure, 6, is obtained using $\mathbf{3}$ as starting configuration. The combined 1st and 2nd EA is $-8.10 \mathrm{eV}$ for $\mathbf{3}+2 e^{-} \rightarrow \mathbf{6}$. In the electron transfer process, $\mathrm{O}_{\mathrm{C}}$ moves away from the Si surface. Therefore, only one major binding site between the F-atom and the Li atoms is found in 6. Analogous to Configuration 4, most negative charge transfers to the $\mathrm{Si}_{15} \mathrm{H}_{16}$ cluster in $\mathbf{5}$ and $\mathbf{6}$. However, there is significant ngative charge ( $~ 84 \%)$ flowing into the FEC molecule. For example, the net charge of FEC in $\mathbf{5}$ is $-0.15|e|$ in comparison to $0.07|e|$ in 1.

Next we examine the first step of bond dissociation for both one- and two-electron decomposition mechanisms. Five bond-breaking modes A-E (not to be confused with configuration labels in the main text) are illustrated in Fig. ??. For one electron mechanisms, bond cleavage occurs via A, B, C, D and B/D. DFT calculations fail to locate intermediates and transition states for bond-breaking mode E. Hence C-F breaking may not be viable as an one-electron mechanism. The corresponding reaction energies $\left(E_{\text {reac }}\right)$ and energy barriers $\left(E^{*}\right)$ are listed in Table ??. $E_{\text {reac }}$ vary between $-0.48 \mathrm{eV}$ and $0.68 \mathrm{eV}$. Bond cleavages via A, $\mathrm{D}$, and $\mathrm{B} / \mathrm{D}$ are exothermic whereas $\mathrm{B}$ and $\mathrm{C}$ are endothermic. This indicates that $\mathrm{C}_{\mathrm{E}^{-}} \mathrm{O}$ bond-breakings are thermodynamically favorable for the one-electron mechanism. However, they are not kinetically favorable due to the relatively high energy barrier $(1.14-1.57 \mathrm{eV})$. The lowest energy barrier is $\mathrm{C}_{\mathrm{c}^{-}} \mathrm{O}$ cleavage (mode $\mathrm{C}$ ), with a value of $0.43 \mathrm{eV}$. The intermediates usually have more binding site(s) on the $\mathrm{Si}$ surface, primarily via the $\mathrm{O}$ and $\mathrm{C}_{\mathrm{E}}$ atoms.

Four bond-breaking modes, A/D, B, C and E are identified for two electron mechanisms (Table ??. The reactions are more exothermic $(-1.86--2.85 \mathrm{eV})$ than those in one electron reactions. Although bond-breaking mode A/D exhibits the most negative reaction energy, its high energy barrier $(1.24 \mathrm{eV})$ makes the bond cleavage kinetically less favorable. One the other hand, bond cleavages at $\mathrm{B}$ and $\mathrm{C}$ show very low energy barriers $(0.11$ and $0.28 \mathrm{eV})$. Therefore, $\mathrm{C}_{\mathrm{C}}-\mathrm{O}$ bond breakings via the two-electron mechanism are both thermodynamically and kinetically favorable on the $\mathrm{Li}_{-} \mathrm{Si}_{15} \mathrm{H}_{16}$ cluster. This is in full agreement with 
the AIMD calculations. Bond breaking at B leads to the formation of intermediate $\mathbf{7}$, in which 3 binding sites, $\mathrm{O}_{\mathrm{C}^{-}} \mathrm{Li}, \mathrm{C}_{\mathrm{C}^{-}} \mathrm{Si}$, and $\mathrm{O}_{\mathrm{E}^{-}} \mathrm{C}$, are observed (Fig. ??). The multi-bindings stabilize the intermediate, and therefore may facilitate the reduction process. The corresponding low-barrier transition state, TG, is associated with formation of a $\mathrm{C}_{\mathrm{C}-\mathrm{Si}}$ bond and cleavage of a $\mathrm{C}_{\mathrm{C}^{-}} \mathrm{O}$ bond as well. Furthermore, C-F bond breaking is found to be feasible with two-electron reduction. In intermediate $\mathbf{8}$, a Li-F bond is formed on the Si surface, and the ring structure is also adsorbed on the surface (Fig ??). Its transition state involves the dissociation of $\mathrm{C}-\mathrm{F}$ and the formation of Li-F, with a barrier of $0.72 \mathrm{eV}$. C-F bond breaking is also found in AIMD simulations. In summary, two electron mechanisms are favorable for FEC reduction on the Li-absorbed Si cluster while one electron mechanisms are either endothermic or exhibit high barriers. Whether one- or two-electron routes dominate depends on electron transfer processes, which are beyond the scope of this study. 
1 Advances in lithium-ion batteries, edited by van Schalkwijk, W.A. \& Scrosati, B. (Kluwer, New York, 2002).

2 Lithium-ion batteries: solid-electrolyte interphase, edited by Wang Y.; Balbuena P.B. (Imperial College, London, 2004).

3 K. Xu, Chem. Rev. 104, 4303 (2004).

4 P. Verma, P. Maire, and P. Novák, Electrochim. Acta 55, 6332 (2010).

5 D. Aurbach, Y. Gofer, M. Ben-Zion, and P. Aped, J. Electroanal. Chem. 339, 451 (1992).

6 W.-J. Zhang, J. Power Sources 196, 13 (2011).

7 S.W. Lee, M.T. McDowell, L.A. Berla, W.D. Nix, and Y. Cui. Proc. Natl. Acad. Sci. 109, 4080 (2012).

8 L.Q. Zhang, X.H. Liu, Y. Liu, S. Huang, T. Zhu, L. Gui, S.X. Mao, Z.Z. Ye, C.M. Wang, J.P. Sullivan, and J.Y. Huang, ACS Nano 5, 4800 (2011).

9 D.E. Arreaga-Salas, A.K. Sra, K. Roodenko, Y.J. Chabal, and C.L. Hinkle, J. Phys. Chem. C 116, $9072(2012)$.

10 M.A. McArthur, S. Trussler, and J.R. Dahn, J. Electrochem. Soc. 159, A198 (2012).

11 C.K. Chan, R. Ruffo, S.S. Hong, and Y. Cui, J. Power Sources 189, 1132 (2009).

12 R. Ruffo, S.S. Hong, C.K. Chan, Huggins, R.A., and Y. Cui, J. Phys. Chem. C 113, 11390 (2009).

13 Y.-C. Yen, S.-C. Chao, H.-C. Wu, and N.-L. Wu, J. Electrochem. Soc. 156, A95 (2009).

14 S.P.V. Nadimpalli, V.A. Sethuraman, S. Dalavi, B. Lucht, M.J. Chon, V.B. Shenoy, and P.R. Guduru, J. Power Sources 215, 145 (2012).

15 M. Nie, D.P. Abraham, Y. Chen, A. Bose, and B.L. Lucht, J. Phys. Chem. C 117, 13403 (2013).

16 B. Philippe, R. Dedryvere, M. Gorgoi, H. Rensmo, D. Gonbeau, and K. Edström, Chem. Mater. 25, 3394 (2013).

17 N.-S. Choi, K.H. Yew, K.Y. Lee, M. Sung, H. Kim, and S.-S. Kim, J. Power Sources 161, 1254 (2006).

18 V. Etacheri, O. Haik, Y. Goffer, G.A. Roberts, I.C. Stefan, R. Fasching, and D. Aurbach, Langmuir, 28, 965 (2012).

19 R. Elazari, G. Salitra, G. Gershinsky, A. Garsuch, A. Panchenko, and D. Aurbach, J. Elec- 
trochem. Soc. 159, A1440 (2012).

20 S. Dalavi, P. Guduru, and B.L. Lucht, J. Electrochem. Soc. 159 A642 (2012).

21 H. Nakai, T. Kubota, A. Kita, and A. Kawashima, J. Electrochem. Soc. 159, A798 (2011).

22 I.A. Profatilova, C. Stock, A. Schmitz, S. Passerini, and M. Winter, J. Power Sources 222, 140 (2013).

23 K.C. Klavetter, S.M. Wood, Y.-M. Lin, J.L. Snider, N.C. Davy, A.M. Chockla, D.K. Romanovicz, B.A. Korgel, J.-W. Lee, A. Heller, and C.B. Mullin, J. Power Sources 238, 123 (2013).

24 M. Gauthier, D. Mazouzi, D. Reyter, B. Lestriez, P. Moreau, D. Guyomard, and L. Roué, Energy Environ. Sci. 6, 2145 (2013).

25 M.A. McArthur, S. Trussler, and J.R. Dahn, J. Electrochem. Soc. 159, A198 (2012).

26 Even the formation of SEI films from unsubstituted ethylene carbonate (EC) molecules and cosolvent diethyl carbonate (DEC), used as standard laboratory electrolyte, has arguably not been completely understood $27 \sqrt[28]{2}$

27 I.A. Shkrob, Y. Zhu, T.W. Marin, and D.P. Abraham, J. Phys. Chem. C 10.1021/jp406274e (2013).

28 K. Leung, Chem. Phys. Lett. 568-569, 1 (2013).

29 R. Mogi, M. Inaba, Y. Iriyama, T. Abe, and Z. Ogumi. Langmuir 19, 814 (2003).

30 L. Chen, K. Wang, X. Xie, and J. Xie, J. Power Sources 174, 538 (2007).

31 Y. Wang, S. Nakamura, M. Ue, and P.B. Balbuena, J. Am. Chem. Soc. 123, 11708 (2001).

32 Y. Wang and P.B. Balbuena, J. Phys. Chem. B, 106, 4486 (2002).

33 Y. Wang, S. Nakamura, K. Tasaki, and P.B. Balbuena, J. Am. Chem. Soc., 124, 4408 (2004).

34 Y.-K. Han and S.U. Lee, Theor. Chem. Acc. 112, 106 (2014).

35 D. Bedrov, G.D. Smith, and A.C.T. van Duin, J. Phys. Chem. A 116, 2978 (2010).

36 M.D. Halls and K. Tasaki, J. Power Sources 195, 1472 (2010).

37 H. Tavassol, J.W. Buthker, G.A. Gerguson, L.A. Curtiss, and A.A. Gewirth, J. Electrochem. Soc. 159, A730 (2010).

38 K. Leung, J. Phys. Chem. C 117, 1539 (2013).

39 P. Johari, Y. Qi, and V.B. Shenoy, Nano Lett. 11, 5494 (2011).

40 B.R. Long, M.K.Y. Chan, J.P. Greeley, and A.A. Gerwirth, J. Phys. Chem. C 115, 18916 (2011). 
41 M.K.Y. Chan, C. Wolveton, and J.P. Greeley, J. Am. Chem. Soc. 134, 14362 (2012).

42 M.K.Y. Chan, B.R.. Long, A.A. Gerwirth, and J.P. Greeley, J. Phys. Chem. Lett. 2, 3092 (2011).

43 Y. Okamoto, J. Phys. Chem. C 115, 25160 (2011).

44 P. Lu and S.J. Harris, Electrochem. Commun. 13, 1035 (2011).

45 E. Peled, Lithium Batteries (Academic Press, London, 1983).

46 A.M. Andersson, A. Hemingson, H. Siegbahn, U. Jansson, and K. Edström, J. Power Sources 119, 522 (2003).

47 V.L. Chevrier, J.W. Zwanziger, and J.R. Dahn, Journal of Alloys and Compounds, 496, 25 (2010).

48 C. Ban, B.B. Kappes, Q. Xu, C. Engtrakul, C.V. Ciobanu, A.C. Dillon, and Y. Zhao, Appl. Phys. Lett. 100, 243905 (2012).

49 W.Q. Li and S.H. Garofalini, Solid State Ionics 166, 365 (2004).

50 U. Khalilov, G. Pourtois, A. Bogaerts, A.C.T. van Duin, and E.C. Neyts,i Nanoscale 5, 719 (2013).

51 B. Philippe, R. Dedryvere, J. Allouche, F. Lindgren, M. Gorgoi, H. Rensmo, D. Gonbeau, and K. Edström, Chem. Mater. 24, 1107 (2012).

52 Since similar organic functional groups are identified on Si and graphite anode surfaces, the pertinent SEI formation mechanisms is likely similar for both anode materials. One ready explanation is the cracking of $\mathrm{Li}_{x} \mathrm{Si}_{y}$ particles exposing pristine surfaces to allow 2-electron reduction.

53 G. Kresse, G. and J. Furthmüller, J. Phys. Rev. B 54, 11169 (1996); Comput. Mater. Sci. 6, 15 (1996).

54 G. Kresse and D. Joubert, Phys. Rev. B 59, 1758 (1999).

55 J.P. Perdew, K. Burke, K., and M. Ernzerhof, Phys. Rev. Lett. 77, 3865 (1996).

56 In DFT/PBE simulations of water, it is well known that elevated temperature is needed to reproduce experimental pair correlation at T=300 K. See, e.g., E. Schwegler, J.C. Grossman, F. Gygi, G. Galli, J. Chem. Phys. 121, 5400 (2004).

57 J.M. Martinez and P.B. Balbuena (unpublished).

58 K. Leung and J.L. Budzien, Phys. Chem. Chem. Phys. 12 (2010) 6583.

59 K. Leung, Y. Qi, K.R. Zavadil, Y.S. Jung, A.C. Dillon, A.S. Cavanagh, S.H. Lee, and 
S.M. George, J. Am. Chem. Soc. 133, 14741 (2011).

60 K. Ushirogata, K. Sodeyama, Y. Okuno, and Y. Tateyama, J. Am. Chem. Soc. 135, 11967 (2013).

61 K. Leung and C.M. Tenney, J. Phys. Chem. C 117, 24224 (2013).

62 G. Henkelman, A. Arnaldsson, and H. Jonsson, Computational Materials Science 36, 354 (2006).

63 Gaussian 09, Revision A.1, M.J. Fritsch et al., Gaussian, Inc., Wallingford CT, 2009.

64 A.V. Marenich, C.J. Cramer, and D.G. Truhlar, J. Phys. Chem. B 113, 6378 (2009).

65 A.D. Becke, J. Chem. Phys. 98, 5648 (1993).

66 C.T. Lee, W.T. Yang, and R.G. Parr, Phys. Rev. B 37, 785 (1988).

67 J.P. Perdew, K. Burke, and Y. Wang, Phys. Rev. B 54, 16533 (1996).

68 Z. Wang, J. Xu, W.-H. Yao, Y.-W. Yao, and Y. Yang, ECS Trans. 41, 29 (2012).

69 C.M. Breneman and K.B. Wiberg, J. Comput. Chem. 11, 361 (1990).

70 Y. Ma and P.B. Balbuena (unpublished).

71 V.S. Bryantsev, V. Giordani, W. Walker, J. Uddin, I. Lee, A.C.T. van Duin, G.V. Chase, and D. Addison, J. Phys. Chem. C 117, 11977 (2013). 


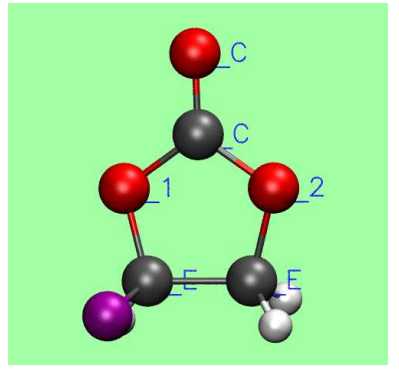

(a)

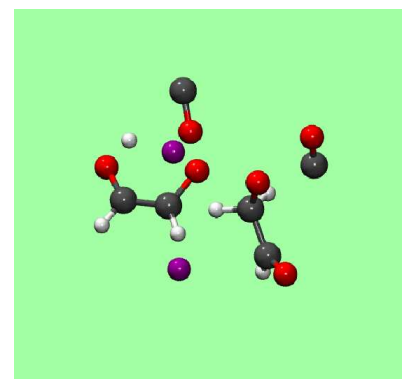

(b)

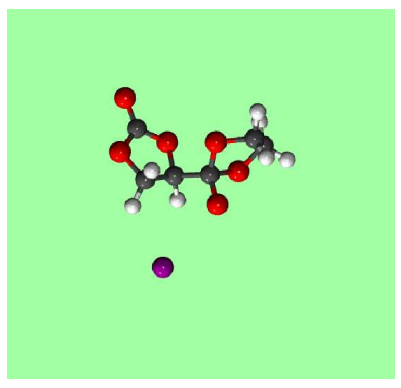

(c)
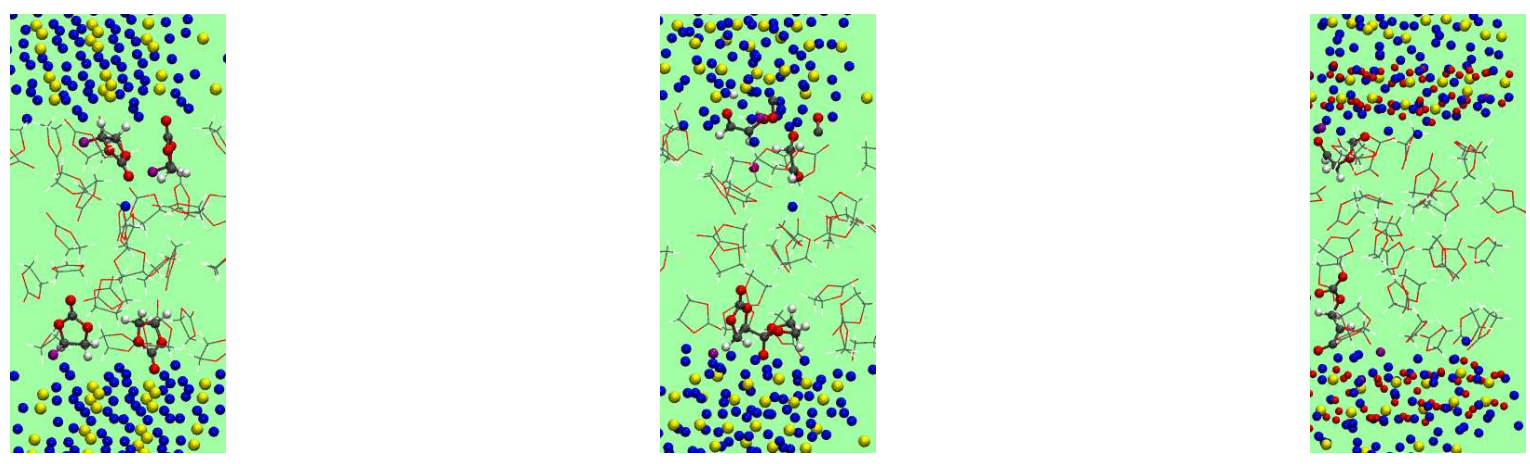

(d)

(e)

(f)

FIG. 1: (a) FEC molecule with labels. C, O, H, and F atoms are depicted as grey, red, white, and purple spheres. (b)\&(c) Expanded views of decomposed molecules on the top and bottom sides of panel (e), omitting the $\mathrm{Li}_{13} \mathrm{Si}_{4}$ slab. (d)\&(e) Configurations at times $t=0$ and $t=4$ ps into an AIMD simulation of a $\mathrm{Li}_{13} \mathrm{Si}_{4}$ slab immersed in liquid FEC/EC. Si, Li, C, O, H, and F atoms are depicted as yellow, blue, grey, red, white, and purple lines or spheres. In (d), 3 FEC and 1 EC molecules at the surface, about to react, are depicted as ball-and-stick models. In (e), these 3 FEC and 1 EC that have reacted. Other reactions are omitted. (f) Liquid FEC in contact with $\mathrm{Li}_{4} \mathrm{SiO}_{4}$ coated $\mathrm{Li}_{13} \mathrm{Si}_{4}$ anode slab, also leading to two- $2 \overline{5}$ reduction reactions. 


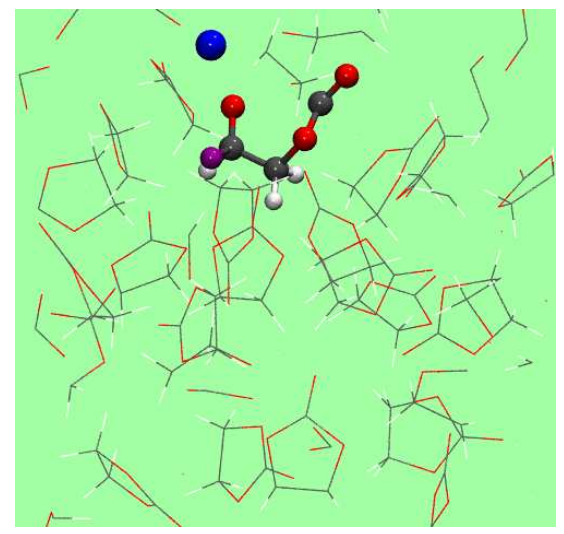

FIG. 2: Configuration at the end of a 5.3 ps AIMD trajectory in the absence of an electrode. Solid spheres highlight the breaking of the $\mathrm{C}_{\mathrm{C}}-\mathrm{O}_{1}$ bond. $\mathrm{Li}^{+}$is coordinated to between 3 and 4 O-atoms on $\mathrm{FEC}^{-}$and EC molecules (the latter shown as lines). 


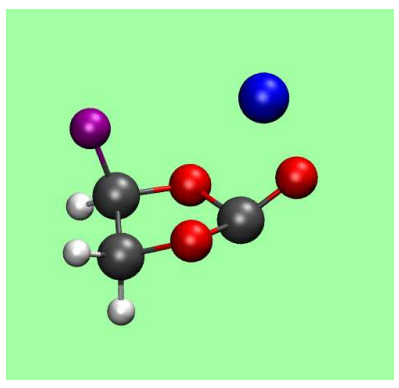

(a):A

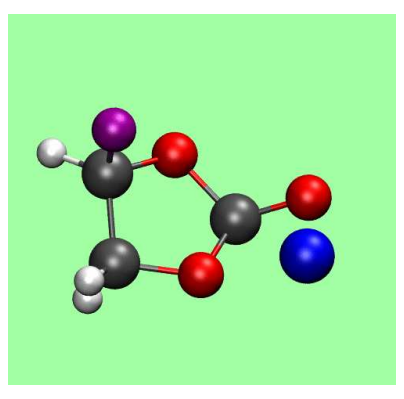

$(\mathrm{d}): \mathrm{D}$

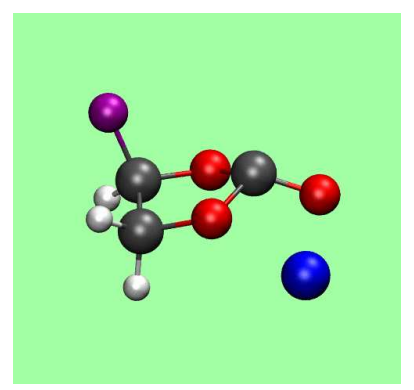

(b):B

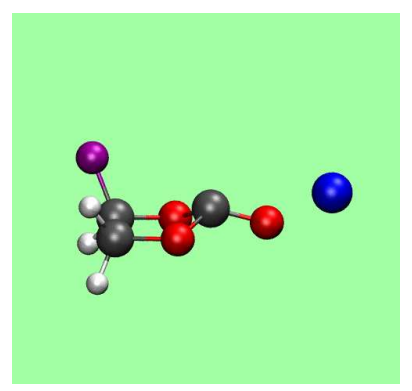

(e):E

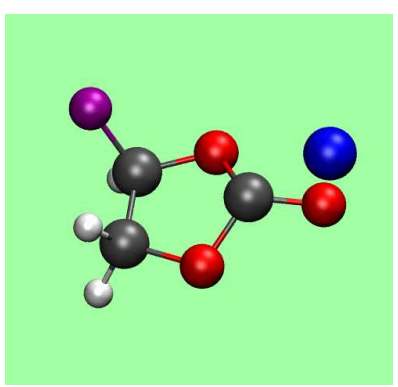

(c):C

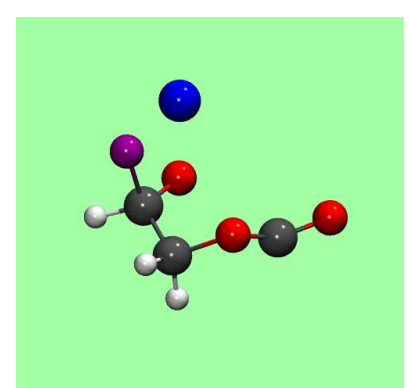

(f):F

FIG. 3: Panels (a)-(f): $\mathrm{FEC}^{-}: \mathrm{Li}^{+}$clusters. Configurations A-F. $\mathrm{Li}^{+}$is coordinated to two O atoms of $\mathrm{FEC}^{-}$in panels (a)-(d) and only one $\mathrm{O}$ in panel (e). 


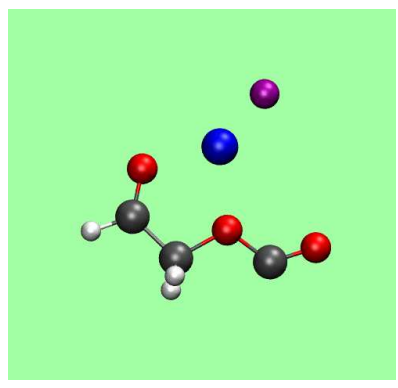

(a):G

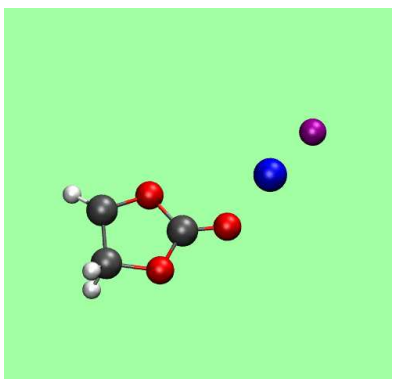

(d):J

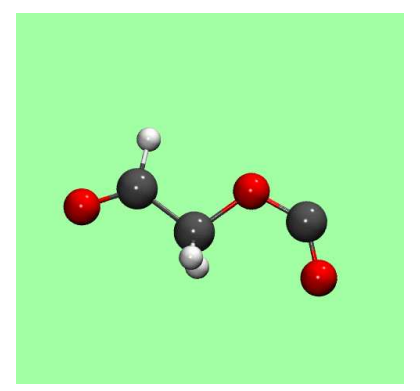

(b):H

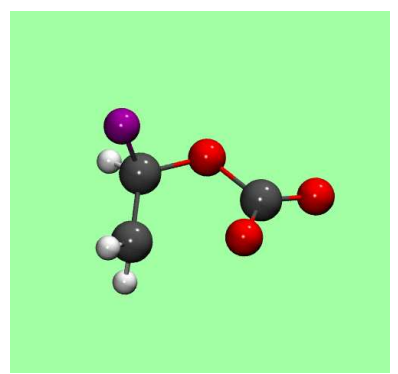

$(\mathrm{e}): \mathrm{K}$

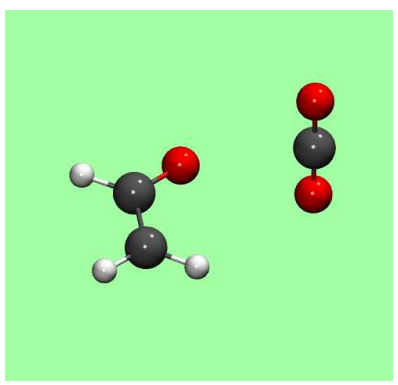

(c):I

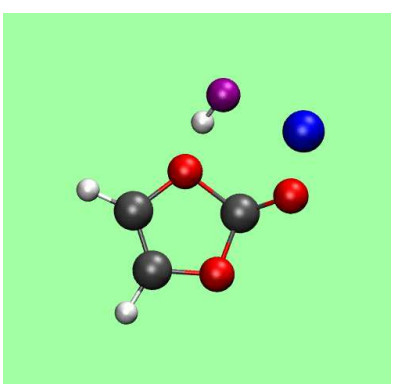

$(\mathrm{f}): \mathrm{L}$

FIG. 4: Configurations G-L depict broken $\mathrm{FEC}^{-}$. Panel (b) is the same fragment as (a) after removing $\mathrm{Li}^{+}$and $\mathrm{F}^{-}$and re-optimizing. The total energy of panel (d) is computed using two separate calculations for $\mathrm{CO}_{2}$ and $\mathrm{CH}_{2} \mathrm{CHO}$. The most favorable pathway is $\mathbf{A} \rightarrow \mathbf{F} \rightarrow \mathbf{G} / \mathbf{H} \rightarrow \mathbf{I}$. Note that a $90^{\circ}$ rotation about the $\mathrm{C}-\mathrm{C}$ bond in $\mathbf{H}$ is needed in the transition state to eliminate $\mathrm{CO}_{2}$. 


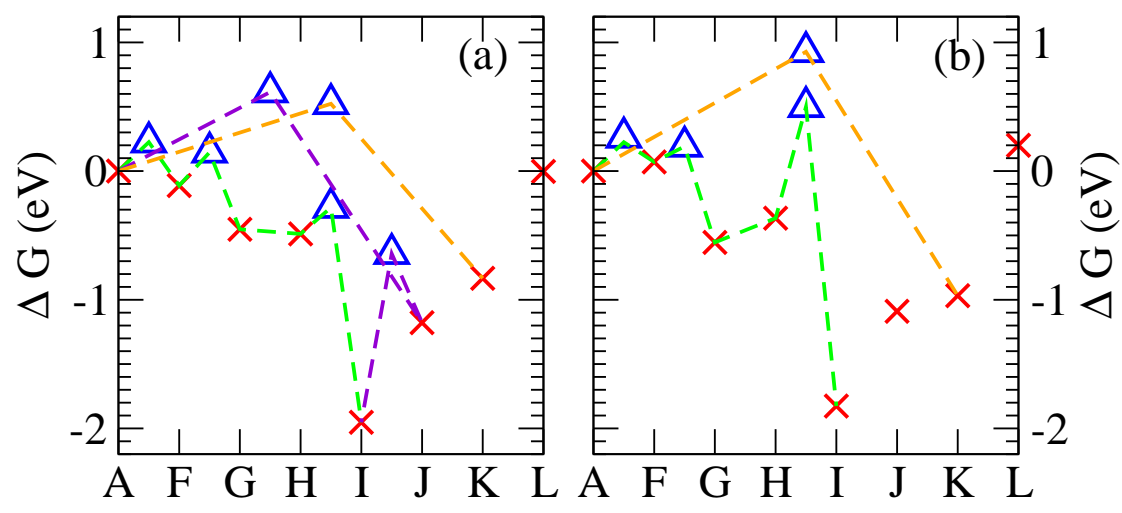

FIG. 5: Free energies of intermediates (crosses) and barriers (triangles) associated with configurations $\mathbf{A}, \mathbf{F}, \mathbf{G}, \mathbf{H}, \mathbf{I}, \mathbf{J}$, and $\mathbf{K}$. (a) PBE predictions; (b) MP2. The path depicted in green is most favored. $\mathbf{G}$ and $\mathbf{H}$ differ by $\mathrm{Li}^{+} / \mathrm{F}^{-}$diffusing away. 


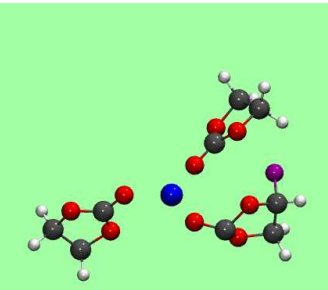

(a):M

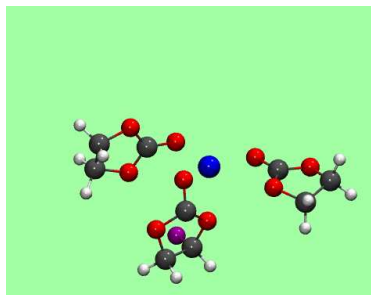

(b):N
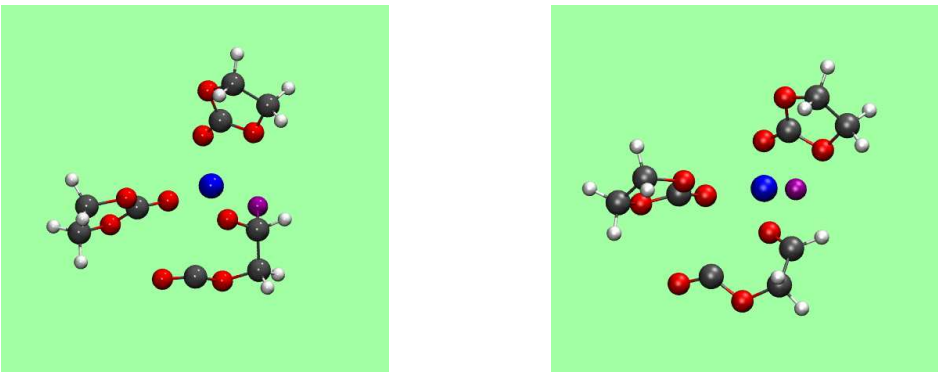

(d):P

(c):O

FIG. 6: Configurations M-P, using $\mathrm{Li}^{+}: \mathrm{FEC}^{-}(\mathrm{EC})_{2}$ cluster models. 
(a)
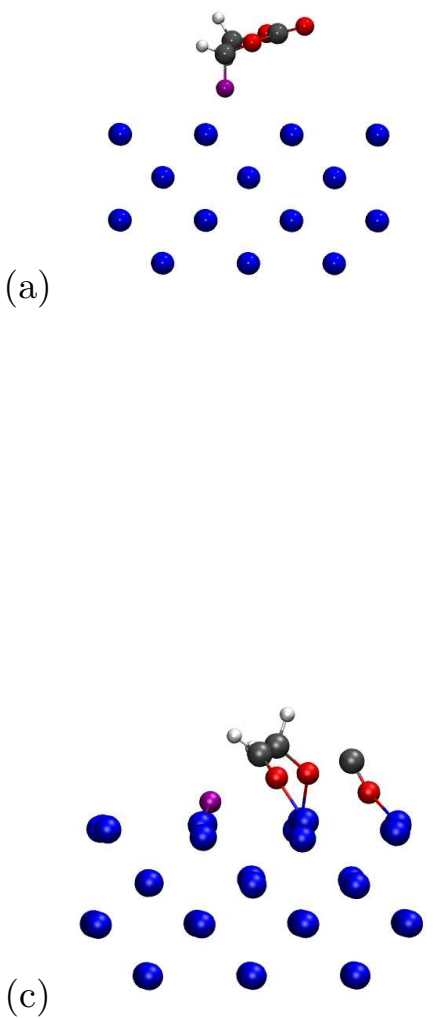

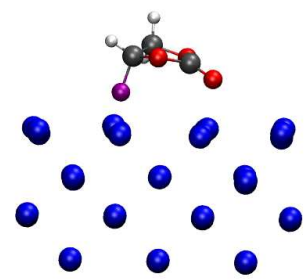

(b)

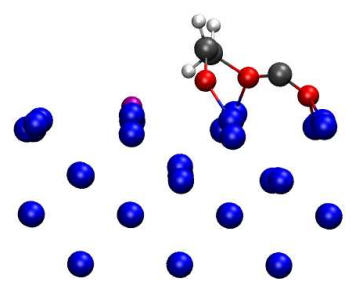

FIG. 7: Images of the decomposition of FEC on a Li surface as observed upon geometry optimization at the B3LYP/6-31G level of theory using the "smd" dielectric continuum approximation. The panels depict optimization step number 0, 20, 40, and 100, respectively. 


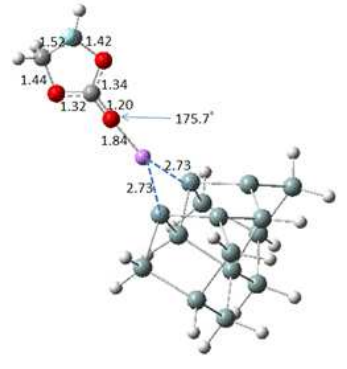

1

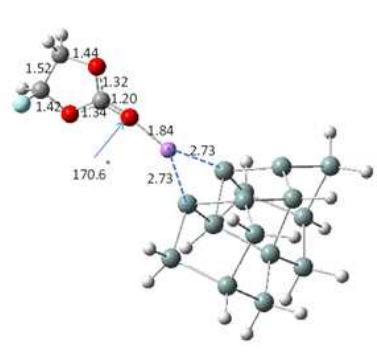

2

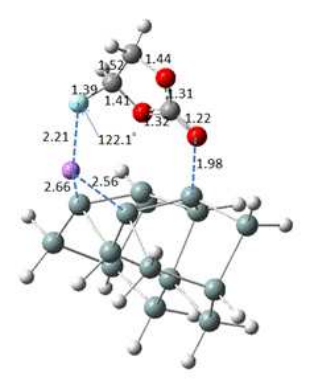

3

FIG. 8: Calculated geometries for FEC adsorption on the $\mathrm{Si}_{15} \mathrm{H}_{16}-\mathrm{Li}^{+}$complex. C, O, H, F, Li and Si atoms are depicted as grey, red, white, light blue, blue grey and purple spheres, respectively. Distances are in $\AA$. 